\title{
ENTREVISTA Ronilso Pacheco
}

Ronilso Pacheco é graduado em Teologia pela Pontifícia Universidade Católica do Rio de Janeiro (PUC-Rio), bem como ativista, pastor auxiliar na Comunidade Batista, em São Gonçalo, autor do livro Ocupar, resistir, subverter (2016) e do artigo "Teologia negra: o sopro antirracista do espírito" (2019). Mestrando em teologia pelo Union Theological Seminary (Columbia University), em Nova York (EUA).

Gabriel Banaggia: O tema que foi pensado para esse dossiê foi "Religião e pensamentos minoritários", sob dois diferentes aspectos: por um lado, fala de religiões que numericamente são minorias, como é o caso das religiões afro-brasileiras. Por outro, aborda pensamentos minoritários no interior de religiões que são majoritárias. Então, a gente sabe que no Brasil o cristianismo é majoritário, mas o protestantismo, as religiões evangélicas, não necessariamente são majoritários. E no interior das religiões evangélicas a gente sabe que existem diferentes vertentes, alas, correntes de pensamento também que podem ser minoritários, e a antropologia costuma prestar bastante atenção às manifestações que são consideradas minoritárias, sendo que isso de forma alguma significa que elas sejam menores, de menor importância, talvez seria possível dizer praticamente o contrário. Então esse seria o tema que leva para minhas primeiras perguntas: você acha que essa impressão procede em relação às religiões evangélicas? Faz sentido falar na ideia de uma religião não querer ser necessariamente majoritária? Isso acontece em alguma medida com o protestantismo? E uma outra questão que estaria relacionada seria: como é que esse tipo de oposição talvez altera, transforma ou modifica o tipo de argumentação, especialmente argumentação na esfera pública, que é mobilizada para que se possa efetivar direitos? Direitos de liberdade de culto, de expressão, que em tese deveriam ser de todas as religiões.

\footnotetext{
${ }^{1}$ Entrevista concedida a Gabriel Banaggia para a Desigualdade \& Diversidade, em 4 de outubro de 2020. 0 texto foi editado tendo em vista concisão e inteligibilidade, e a versão aqui publicada foi revista e aprovada pelo entrevistado.
} 
Ronilso Pacheco: Em grande parte, esse princípio da expansão está muito relacionado com o universo cristão de uma maneira geral, mas com o universo evangélico muito maior, que o catolicismo também tem essa qualidade da missão e da ocupação dos espaços, mas até de uma perspectiva muito institucional mais coletiva, enquanto o universo evangélico tem muita ênfase no indivíduo, na expansão de cada sujeito, de cada indivíduo ser alcançado pelo evangelho, pela verdade cristã. Então isso é algo que está realmente muito intimamente ligado com o universo evangélico. E aí há várias questões, mas uma delas é a de pensar no contexto brasileiro atual, por exemplo. Pensar esse projeto, essa identidade da expansão, que é uma compreensão da ideia do discipulado, de se fazer discípulos, que já tem uma disputa em termos de sentido. Há um consenso entre muitos estudiosos dos Evangelhos, sobre os textos e o sentido de quando Jesus está falando de fazer discípulos: não é uma fala necessariamente pela perspectiva da conquista, de conquistar a pessoa no sentido de conquistar territórios, mas no sentido de você ser tão referencial e inspirador que você faz com que outras pessoas almejem ter o seu caráter suas atitudes. É muito mais como essas práticas inspiram, e isso fazer com que outras pessoas se interessem em seguir o teu caminho, do que propriamente uma estratégia, um projeto de conquista, de fazer com que pessoas confessem a sua fé. Então, essa também é uma disputa interessante. É claro que esse modelo não interessa muito a projetos de poder. O que interessa a projetos de poder é a perspectiva da expansão, da conquista de territórios e lugares, e dentro do cristianismo, de se ter a centralidade. Pensando nessa disputa, a gente pensa na conquista brasileira, na realidade brasileira, sim, tem um grande desejo, do evangelicalismo hegemônico, de ser majoritário, e não apenas de ser majoritário, mas de marcar esse lugar como maioria e, a partir de ser maioria, ter o poder de decisão e o poder de condução país e de construção de formação de sociedade, a sociedade a partir daquilo que a maioria determina e experimenta. Essa mistura de ser uma religião de fato majoritária, mas não apenas majoritária numericamente, mas majoritária no sentido do poder de decisão, nas decisões da esfera pública etc. Por outro lado, nós sempre tivemos, e não é diferente hoje, também essa corrente que a gente pode identificar aqui como as vozes minoritárias ou minorizadas dentro do universo evangélico, que na verdade questiona esse lugar do majoritário, na medida em que esse ser majoritário não significa uma diferença qualitativa positiva para a sociedade, essa é uma grande discussão. Se você tem um projeto semelhante ao que Jesus pensou como maioria, a ideia é que você teria uma sociedade completamente diferente em termos de solidariedade. Mas é exatamente o contrário, a situação que a gente tem é: quanto mais forte a igreja evangélica hegemônica se torna, quanto mais majoritário o campo evangélico conservador, sobretudo, a sociedade fica mais retrógrada, mais difícil, mais conservadora e fundamentalista em alguns aspectos. Então você tem dentro de todo esse movimento evangélico, vozes que estão pensando muito 
menos na perspectiva majoritária e muito mais no impacto positivo e necessário que a religião evangélica pode ter. E dentro da realidade que nós temos hoje, que de fato a religião evangélica não é majoritária em termos de número, mas a gente tem uma grande sensação de que ela é majoritária porque ela está muito presente em tudo, nos debates, na política, nas decisões das eleições, isso dá uma sensação de ubiquidade, de onipresença do universo evangélico, que às vezes é preciso ver os números para lembrar que o catolicismo ainda é maior. O protagonismo do universo evangélico é muito forte, e claro que isso tem impactos muito deletérios para a sociedade, porque esse crescimento com a perspectiva de se tornar majoritário, da conquista, ele quase que necessariamente está pautado numa neutralização de direitos distintos, ele pensa muito menos na diversidade e muito mais em como cobrir essa diversidade com as diretrizes, com as orientações, com a formatação social da religiosidade, e da religiosidade evangélica. Então acho que esse é o conflito: existe o campo evangélico que trabalha para se tornar majoritário, por dentro dele vozes minoritárias e movimentos minoritários que questionam esse crescimento, esse projeto de se tornar majoritário, esse projeto de se estabelecer como uma maioria cristã, e as consequências disso para o entorno, que é uma espécie de supressão e neutralização do reconhecimento de direitos da diversidade religiosa, da diversidade social, da pluralidade na esfera pública.

GB: A pergunta seguinte é um pouco sobre seu perfil e trajetória: você é ao mesmo tempo um líder religioso, com formação e atuação acadêmica, um autor muito prolífico, está muito presente na esfera pública. Então há também participação na grande mídia, como colunista em grandes meios de comunicação. Conjugando todas essas diferentes inserções, como você diria que cada uma dessas posições afeta o que você produz em relação às outras? O que diferencia essa atuação nas distintas frentes justamente por você atuar nelas todas quase simultaneamente?

RP: Eu acho que um grande diferencial é exatamente esse lugar e essa história no campo religioso. Acho que nós estamos num momento, principalmente no Brasil, em que a religião tem sido muito protagonista. A religiosidade tem sido muito protagonista, ou a institucionalidade, as religiões institucionais, têm tido um protagonismo muito forte. Tanto no meu campo, no campo cristão evangélico por razões óbvias, que você conhece, quanto no campo das religiões matriz africana, que estão numa outra ponta, no sentido da perseguição, da luta por direitos, de uma construção de unidade também, uma frente de resistência, coletiva e atuante, do estabelecimento de um sentido de uma visão política e social numa construção de coletividade. Esse histórico é parecido nas religiões de matriz africana, mas que nos últimos anos tem sido cada vez mais forte e organizado, de uma maneira mais em rede, também, então acho que esse é o diferencial, é nossa religiosidade ou pertencimento 
religioso, que afeta todas as outras coisas feitas. Escrever num veículo de grande circulação é importante, mas o diferencial que inclusive faz com que nós cheguemos lá é que esse filtro está muito mais apurado, digamos assim, o universo evangélico é muito complexo e tem muitas sutilezas, muitas diferenças, muita diversidade, são muitas armadilhas quando você trata a questão dos evangélicos, e a gente tem visto isso, sempre o eterno debate dos evangélicos nas eleições. Acho que é esse pertencimento que permite ser mais apurado, por uma história, uma jornada, pelo tempo de caminhada, por coisas vistas, e isso na verdade marca todas as outras coisas feitas. Se eu faço uma produção acadêmica, se é um artigo, até com temáticas que em tese não têm nada a ver com elas, mas na verdade elas são cruzadas por ela, ela é atravessada pela religiosidade também, como a religião legitima ou enfrenta determinadas questões. Esse é o ponto que influencia tudo que marca as outras ações que nós temos, e nossas atuações mostram um pouco isso também: como a religiosidade é transversal, e atravessa diversas dimensões da vida, de conquistas ou de lutas, de resistência, de aspirações políticas etc., mas elas são muito entrecortadas pela religiosidade ou pela influência que a religião tem.

GB: Eu vou antecipar uma pergunta que eu tinha pensado para adiante, por causa de algo que você comentou em relação à presença e participação na academia, mais especificamente. A gente sabe que a academia é um lugar que procura se apresentar como muito diverso, mas que muito frequentemente também produz e reproduz racismo. Então que tipo de iniciativas você diria que daria para enxergar com bons velhos em relação ao enfretamento ao racismo na academia e ao mesmo tempo, inversamente, quais iniciativas você acha que ainda estão longe de produzir os efeitos desejados para enfrentar isso realmente, esse problema no interior do meio universitário?

RP: Eu acho que para mim, particularmente, uma experiência muito marcante foi a do coletivo Nuvem Negra, na PUC-Rio e eu acho que ela sintetiza um pouco em termos de exemplos e alternativas. Claro que as políticas precisam legitimar essas ações, mas acho que as alterações no dia a dia conquistadas pelo coletivo Nuvem Negra na PUC-Rio, com eventos com muita centralidade de figuras negras importantes, pensadores negros importantes, sobretudo a interferência no dia a dia das próprias aulas, no ensino na Universidade: quando o coletivo conseguiu que a Reitoria aprovasse a aquisição de livros para biblioteca, diversos pensadores negros que nós não tínhamos... Por incrível que pareça, você dificilmente achava um livro do Cornel West, por exemplo, parece surreal, mas era difícil você encontrar, só tem uma ou duas traduções, mas mesmo em inglês, você também não tinha. A intervenção na bibliografia das matérias, ter a oportunidade de sugerir pensadores e autores negros para a bibliografias, que ao longo de tantos anos nunca tiveram um único pensador, um único autor 
negro incluído. Mesmo brasileiros importantes. Lélia Gozalez não constava em bibliografia de curso praticamente nenhum, somente de Ciências Sociais, e ela foi diretora do Departamento de Ciências Sociais. Uma intelectual extremamente produtiva, muito atuante. Abdias do Nascimento, você não tinha nenhuma disciplina que passasse por aí, mesmo um sociólogo como Guerreiro Ramos, você não tinha um Guerreiro Ramos na sua bibliografia. Então essas conquistas são determinantes, e ao mesmo tempo são uma resposta a iniciativas importantes e necessárias. Claro que também se precisa contratar professores negros, mas não apenas contratar professores negros ou se ter autores negros numa disciplina como pensamento decolonial na América Latina: precisamos de pensadores negros na economia, no direito, na comunicação, no marketing... Marcar esses lugares é extremamente importante. Ao mesmo tempo que essa é uma resposta de experiências que são necessárias para academia, pensar o contrário também é necessário: aderir a políticas institucionais ou colocadas de cima para baixo pelo legislativo, enfim, políticas públicas que são importantes, são necessárias e são exigências e conquistas importantes, mas se elas não tiverem condições de alterar o dia a dia da universidade, quer dizer... Mais do que ter um professor negro: quais são os autores negros que a gente está lendo? Quais são as disciplinas que estão de fato cumprindo o que é o papel da instituição que é a universidade, que é agora universidade no sentido de pluriversidade, não é uma universidade que se restringe a um continente, mas uma universidade pensando no universo, então onde é que estão esses diálogos com o pensamento africano? É claro que nós fomos formados pela filosofia grega, pela filosofia greco-romana, a história greco-romana, mas a gente está em 2020, fazer isso sem esse diálogo com a filosofia africana, por exemplo, a filosofia latina, hoje já não faz sentido. Então, pensando o que não tem surtido efeito, eu acho que é aquela velha discussão com relação à representatividade: a conversa não é sobre pura e simplesmente ter os professores, um cumprir uma tabela de quantidade de professores negros, mas é o quanto você enegrece a formação do conhecimento. Eu acho que esse ainda é o desafio na academia, acho que um debate vai pra além da quantidade de professores negros que você tem, mas o que é que forma. Se você pensa no direito, você tem professores geniais no campo do direito, negros, hoje, mas o direito continua com a mesma base curricular e bibliográfica de sempre, os mesmos autores brancos de sempre, europeus, alguns latinos, mas brancos, sempre. Acho que essa política pura e simplesmente da representatividade, sem a representatividade na bibliografia, não funciona.

GB: Maravilha. A pergunta agora seria sobre o contexto nos Estados Unidos, em relação às igrejas evangélicas historicamente negras. Daria para a gente fazer um paralelo com a nossa formação histórica efetivamente, porque as religiões de matriz africana não conseguiram 
vicejar nos Estados Unidos da mesma forma do que na América Latina, no Brasil em especial, mas as igrejas negras americanas de certa forma oferecem um paralelo interessante, um pouco mais sociológico em relação à formação mesmo, de espaços de resistência, de autonomia, possíveis para a população negra. E isso gerou, claro, um outro tipo de mundo evangélico nos Estados Unidos. Você acha que seria possível tirar algum tipo de aprendizado desse paralelo e é possível permitir uma outra leitura para a teologia negra no Brasil, com base nessa experiência? E, ao mesmo tempo, como é que a gente consegue dissociar discursos de provação da ideia de uma certa resiliência encantada? Dessa ideia de que haveria uma resistência praticamente natural da população negra, algo que tira a ideia de resistência de um polo ativo, primeiro, da resistência de fato como uma vontade, como um desejo e também uma conquista imensa da população negra, para pensar a resistência desse modo mais negativo que a considera apenas como reatividade, como se resistir fosse somente responder a um outro ponto de vista. Como considerar essas iniciativas por esse outro lado, do ponto de vista da autonomia, da deliberação e efetivamente da vontade da população negra?

RP: Respondendo de trás para frente, eu acho que com relação às resistências da população negra, a gente precisa quase de uma revisão histórica, na verdade, porque essa é uma construção, eu diria até deliberada, no sentido de tirar da história da população negra no Brasil essa força, essa criatividade e essa autonomia. Existe uma invisibilidade provocada que dá a sensação de que que não é assim que as coisas aconteceram, não foi assim, mas pelo contrário, toda história de resistência da população negra é marcada exatamente pela autonomia, pela criatividade, pela criação, pelas estratégias diversas. Os quilombos são experiências muito diversificadas de sociabilidade, de sociedade, e aí uma diferença de sociedade que é criativamente uma resistência, um tipo de sociedade escravocrata de onde eles fugiram. Se você pensar, por exemplo, no contexto da ditadura militar, os nomes que vêm à cabeça em termos de resistência com criatividade são sempre os mesmos: Gil, Caetano, e quando você pensa no teatro, você vai pensar no Zé Celso e tudo o mais. E pouco ou quase nada se fala por exemplo da experiência do Abdias Nascimento com o Teatro Experimental do Negro. Como era uma experiência teatral tão potente, tão poderosa, a ponto de ser desconstruída pela ditadura militar, desconstruída com a prisão e o exílio do Abdias. A experiência foi desarticulada de tal maneira que o Abdias foi proibido de participar de um primeiro grande evento para a cultura negra no Senegal, em I966, se não me falha a memória. Organizado pelo [Léopold] Senghor, pelo [Aimé] Césaire, uma resistência extremamente conectada com essa força da criatividade como era o movimento Negritude, mas Clementina de Jesus estava lá, por exemplo, Mestre Pastinha estava lá, com a resistência a partir da capoeira. A capoeira não apenas como uma luta de resistência, de enfrentamento, mas como uma outra proposta de direcionamento, filosoficamente como uma arte, nesse sentido da arte 
marcial como uma forma de pensamento. Então, as resistências sempre foram marcadas por autonomia e criatividade. A grande questão, volto para o início da resposta, é quase que uma revisão histórica. Quando você pergunta, como dissociar isso? Como desconstruir isso? Desconstruir isso é ver como em vários momentos da nossa história essa resistência com criatividade, com autonomia, com proposição inclusive de sociedade, como ela foi neutralizada, invisibilizada, para construir um mito de uma resistência que é só reativa ou de uma não resistência. Durante muito tempo os quilombos, por exemplo, foram ensinados como um lugar para onde se ia e simplesmente se fugia, não tinha uma proposta, não era nada, só um lugar para os negros se esconderem da sociedade escravocrata. Quer dizer, mesmo se tinha poucos elementos, pelo menos que entrassem na discussão da complexidade de sociabilidade que você tinha em quilombos, que não eram iguais, absolutamente. Isso é como o racismo no Brasil: ele é tão eficiente que essa invisibilidade criou essa consequência, e essa ideia. E aí você fala com relação à igreja negra nos Estados Unidos, e de fato você tem uma presença da religiosidade africana muito remota nos Estados Unidos, principalmente na formação do país, nas lutas, no desenvolvimento dos direitos civis. A luta pelos direitos civis é uma luta basicamente protestante, marcada pela igreja protestante. Agora, é interessante que, em muitos aspectos, em muitas experiências, é um cristianismo, mesmo um pentecostalismo, muito africanizado. São experiências completamente diferentes, e sobre a possibilidade de surgir um outro tipo de evangelicalismo nos Estados Unidos, mesmo assim majoritariamente o que você tem é um evangelismo branco muito forte, um nacionalismo cristão branco muito forte. Mas, de fato, há um movimento paralelo de muita força que eclode sobretudo nacionalmente, a partir dos anos 1960, com o surgimento de uma resistência da comunidade negra muito forte em torno das igrejas e ressignificando, acho que isso é uma coisa importante, ressignificando muito dos sentidos que eram atribuídos pelas igreja evangélicas brancas. Por exemplo, poucos negros, inclusive hoje (a gente frequenta uma igreja negra aqui em Nova York, no Harlem), poucas igrejas negras chamam Jesus de Senhor, por exemplo. Eles chamam Jesus de grande irmão, é o big brother Jesus, algumas falam nosso primeiro ancestral. Então, ressignificando toda uma estrutura pensada a partir desse lugar, que foi formulado, forjado dentro de uma sociedade escravocrata, e essa perspectiva foi extremamente interessante para uma possibilidade de pensar a teologia negra nos Estados Unidos para formar a teologia negra aqui no Brasil, e eu acho que guardadas as devidas proporções, limites e complexidades importantes para pensar como características muito brasileiras, pensar a possibilidade de uma teologia negra de fato no Brasil. Eu acho que a gente não tem uma experiência como essa, você tem experiências mínimas, mas a gente não tem uma experiência como essa, de uma igreja negra, pelo contrário, nosso desafio no Brasil é completamente diferente: como igrejas que são majoritariamente negras podem ser 
desconstruídas do seu racismo religioso com relação às religiões de matriz africana. Então, a gente não tem uma experiência como essa, mas ainda assim acho que a elaboração, a construção, a forma como a hermenêutica foi construída aqui, a partir da experiência das igrejas negras, pode ser ainda determinante para pensar uma possibilidade de diálogo de uma perspectiva teológica de uma teologia negra também para o Brasil.

GB: Temos visto cada vez mais coletivos progressistas despontando com força no interior do mundo evangélico, talvez como fenômenos bem recente, inclusive se organizando para disputar cargos políticos nas eleições deste ano. E isso tem acontecido pautado um pouco mais para enfrentar determinados preconceitos sobre gênero e orientação sexual, que são temáticas que são em geral abordadas de forma muito violenta no pensamento conservador. Você acha que as experiências dessas alas específicas do universo evangélico se comunicam de alguma forma com as experiências de lutas da opressão racial? Você acha que é possível que ambas se fortaleçam mutuamente ou essa é uma interlocução que não acontece?

RP: Desses novos movimentos progressistas, sim. Tanto é que vários de alguma forma se comunicam, se falam. Pelo menos com base na minha própria experiência, há muitos anos vejo como esse caminho com o movimento negro e as lutas de direito à cidade, e a questão de gênero, elas se atravessam. E eu acho que sim, que você tem hoje grandes parcerias e interconexões de movimentos progressistas na temática de gêneros, de desigualdade de gênero, ou mesmo a questão racial, que caminham juntas e que são articuladas com movimentos... vou colocar aqui como 'seculares'. Enfim, movimentos não evangélicos, e isso de muito tempo. Você tem muitos projetos em comum com coletivos evangélicos progressistas sobre gênero, como o Católicas pelo Direito de Decidir, por exemplo e uma outra, o Geledés, para ficar em dois casos. Esse diálogo já acontece, assim como na questão racial também, você tem expoentes, nomes, pessoas importantes no movimento negro evangélico, que têm trabalhos em conjunto com movimentos como a Coalisão Negra, por exemplo, ou com coletivos negros dos seus estados locais. Então, isso já acontece, e tem se fortalecido cada vez mais, nesse movimento relativamente recente. Na verdade, você falou de um grupo progressista e da formação da bancada, quer dizer, você tem atuação de evangélicos progressistas desde antes da ditadura. O campo evangélico progressista vem atuando, mas é interessante observar que você tem uma espécie de segunda geração de progressistas evangélicos que abraçam pautas que até meados da década de I990 estavam ausentes do campo evangélico progressista. Quer dizer, o campo evangélico progressista era muito similar ao que a teologia da libertação estava debatendo: a questão da desigualdade econômica e as discussões de classe, são muito fortes. Lutar contra as desigualdades, as desigualdades estruturais, sociais etc. E é interessante observar que você tem, a partir da 
segunda metade da década de 1990, mais certamente na década de 2000, uma espécie de segunda geração de progressistas que abraçam todo esse debate da questão de gênero, isso tudo mais discutido da década de 2010 para cá: você pega um projeto como o Redoma, projetos que existem em Alagoas, o coletivo das mulheres negras evangélicas, você tem diversos projetos que surgem basicamente a partir dessa década. Projetos que abraçam esses espaços com relação ao aborto, que sempre foi uma questão muito delicada, e ela é abraçada, e você tem o surgimento da frente de evangélicas pela legalização do aborto, para se ter uma ideia. Todas essas pautas ficaram muito à margem no campo progressista mais histórico, mais de classe, e são abraçados por esses grupos, e esses grupos já abraçam a comunicação com grupos que já estavam trabalhando no movimento circular no evangélico já há bastante tempo. Então, sim, temos esses diálogos e são bastante prolíficos.

GB: É interessante que você comentou agora sobre as iniciativas do interior do catolicismo, isso tem a ver com minha próxima pergunta. A relação entre as religiões de matriz africanas e o catolicismo certamente foi marcada por uma história de perseguição e intolerância. E, em um grau certamente distinto, algo parecido poderia ser dito em relação entre o catolicismo e as diferentes denominações evangélicas. A pergunta então seria: qual é o futuro desejável que você conseguiria vislumbrar para as relações entre essas diferentes religiões?

RP: É difícil falar de futuro vislumbrado. Como ter um futuro sem ser muito utópico, pensando no contexto atual? Acho que mais do que vislumbrar, é ter uma esperança. Não sei se consigo vislumbrar, mas, esperança, eu tenho. E aí eu acho que a teologia negra tem uma contribuição importante, inclusive para além dos debates e das grandes discussões acadêmicas teológicas e filosóficas, mas pensando realmente numa teologia que discute a partir da realidade, do contexto da negritude, da realidade da população negra atual, e eu acho que isso não vai ser feito sem um grande esforço metodológico e pedagógico. Não vai ser feito com a gente fazendo uma série de seminários, encontros, debates e mesas, acho isso muito difícil. É um processo reeducacional mesmo, em especial para as igrejas. A gente tentou fazer uma iniciativa como essa em São Gonçalo alguns anos atrás, juntando jovens evangélicos, de juventude evangélica, e juventude de terreiro, para fazer um diálogo para ver o que era possível. Aconteceu só um encontro, mas foi bem interessante, e eu acho que vislumbrar um futuro é vislumbrar um processo que passa por atitudes como essa. Eu acho que é um processo de reeducação sobretudo para as igrejas evangélicas. É um processo de reeducação com relação a uma outra compreensão da religiosidade de matriz africana, sua espiritualidade, sua importância, suas conexões com as histórias bíblicas, inclusive com as narrativas bíblicas, reencontrar a África nas narrativas bíblicas, eu acho que esse é um ponto 
de partida importante, que não é considerado pelas igrejas evangélicas no Brasil, e isso por conta do processo de colonização, quando você invisibiliza a presença negra e africana na Bíblia, e isso evidentemente tem consequências. Então, eu não vislumbro um futuro, exatamente, mas eu vislumbro um longo processo de reeducação, com uma grande estrutura metodológica e pedagógica de mudança de consciência. Em especial com relação às igrejas evangélicas, para uma perspectiva sobre religião de matriz africana e a importância da diversidade religiosa.

GB: E em relação ao catolicismo, você vê atualmente algum espaço no interior talvez mesmo da parte mais institucional da igreja em que essa comunicação poderia ser frutífera?

RP: Esse caminho dá para vislumbrar. Na medida em que a Igreja Católica tem uma estrutura hierárquica muito mais centrada. Eu acho que você tem aonde ir, para você poder pensar numa possibilidade de diálogo. Você tem esforços históricos muito interessantes, das pastorais afro, que têm um trabalho maravilhoso, de décadas. E por que elas não proliferaram? Porque lá em cima, na hierarquia, não houve nenhum acolhimento, nenhuma aceitação. Uma vez que você tenha a possibilidade de, lá em cima, na hierarquia, alcançar essa mudança estrutural, significa que isso, na base, passa a ser possível. Para a realidade das igrejas evangélicas isso é difícil. Você não tem essa hierarquia central, é cada pastor, uma sentença. Você tem que alcançar diversas lideranças, de diversas mentalidades, de diversas formações ideológicas e teológicas, para conseguir. Então eu acho que é possível, acho que a igreja católica já tem um legado, uma experiência, que é bem interessante, e a gente não deve desconsiderar isso pensando só na igreja institucional, mais conservadora, mas pensar nas brilhantes experiências das pastorais afros ao redor do país. Frei Davi está aí com uma resistência histórica de muitos e muitos anos, no Rio, Padre Gegê, Frei Tatá, pessoas que continuam na margem da hierarquia católica, mas mantendo trabalhos extremamente importantes, extremamente prolíficos. Se você não for pensar só na grande igreja institucional, no magistério. Se você não for pensar numa ordem do magistério para poder repensar as religiões africanas, você já tem experiências bem mais consolidadas, evidentemente, até em termos de produção, como os trabalhos do CEBI [Centro de Estudos Bíblicos], já falando sobre negritude, já falando de religiões de matriz africanas, já desconstruindo a ideia de demonização dos orixás etc. Trabalhos que são então até bem mais vanguardistas do que aqueles com os quais nós temos na prática no universo evangélico. Então, no universo católico, eu vislumbro o futuro a partir dessas experiências muito consolidadas que já estão constituídas, mas a grande questão de vislumbrar o futuro é pensar: que hierarquia nós teremos no futuro? Para pensar a igreja católica, para pensar nossos bispos, nossos cardeais. Enfim, você tem um papa flexível, mas tem o cardinalato que é extremamente conservador 
em vários aspectos e em muitos lugares, e isso torna tudo muito difícil. Então, é pensar como é possível uma outra hierarquia católica, capaz de deixar fluir as experiências que já foram construídas nessa direção.

GB: Última pergunta, embora eu não saiba quão respondível ela é, mas eu queria terminar com ela, mesmo assim. Como é possível encontrar forças para combater o ódio, ao mesmo tempo sem deixar de lado uma série de precauções necessárias para não se deixar dominar por esse ódio que se combate? Dito de outra forma, como é que seriam os meios de conseguir canalizar de forma criativa, transformadora, essa ira tão justificada - para usar a expressão cara à religião - que é a causada pelo racismo?

RP: Com relação ao racismo especificamente - acho que isso serve para coisas gerais, mas especificamente para o racismo -, uma saída eu acho que é ter uma consciência de autocrítica muito forte. Eu acho que isso vai te dando limites com relação a algumas coisas e vai fazendo com que você não perca o foco, e repense algumas coisas. Críticas sempre muito contundentes, mas resistentes, uma luta sempre muito contundente, mas sempre sendo capaz de se rever, enfim, de estar aberto para uma autocrítica que ajude você a ver quando se está chegando num determinado ponto que parece que você foi absorvido por aquilo que você está combatendo. Acho que isso é importante. A outra é ter uma rede ativa de autocuidado, eu acho que isso ajuda a fazer com que o ódio não nos corroa de tal maneira. Porque é bem difícil lidar com isso. Acho que para uns mais do que para outros. Você tem graus de intensidade, mas é muito difícil. E aí eu acho que você ter uma boa rede de autoajuda, a quem você pode recorrer, quem você possa abraçar, chorar, de quem você possa ouvir, isso também te puxa, sem perder esse senso de coletividade. Uma boa autocrítica, esse senso de coletividade, e ter uma rede de autoajuda, tudo isso é importante e ajuda você a vislumbrar um mundo que seja maior do que esse conflito, esse é o seu objetivo final. Eu acho que esses são alguns antídotos possíveis para que nós não sejamos tomados pelo ódio que nós combatemos. 